\title{
SPHINCTER PRESERVING RECONSTRUCTION OF ANGLE OF THE MOUTH
}

\author{
Utpal Bordoloi ${ }^{1}$
}

\section{HOW TO CITE THIS ARTICLE:}

Utpal Bordoloi. "Sphincter Preserving Reconstruction of Angle of the Mouth". Journal of Evolution of Medical and Dental Sciences 2015; Vol. 4, Issue 41, May 21; Page: 7229-7232, DOI: 10.14260/jemds/2015/1048

ABSTRACT: Reconstruction of angle of the mouth following excision of benign and malignant lesions using distant flaps invariably produce dribbling due to absent sphincter function and unsatisfactory cosmetic result. However, reconstruction with local flaps with zygomaticus and platysma muscles to reconstruct the orbicularis oris sphincter produce good functional as well as cosmetic result.

KEYWORDS: Angle of the Mouth; Oral Commissure; Reconstruction; Nasolabial Flap.

INTRODUCTION: Reconstruction of moderate post excisional defects of angle of the mouth and adjacent lips with flaps taken from the nasolabial, lower cheek and the submandibular regions give better cosmetic and functional results than reconstructions with distant flaps as the sphincter function can also be restored using zygomaticus and platysma muscles.

PATIENTS AND METHODS: Five cases, of which two cases of squamous cell carcinomas, two cases of squamous papillomas and a case of keratoacanthoma arising from the angle of the mouth and involving the adjacent lips are operated under general anaesthesia. All the patients are above sixty years of age. Full-thickness resection of the lesions are performed under loupe magnification, leaving approximately one centimetre of healthy tissue around the tumours.(1) Position of the neocommissure was planned measuring the distance from a point in the middle of the philtral columns to the commissure of the uninvolved side. This measurement is then transposed to the affected side with hypercorrection of about $5 \mathrm{~mm}$.(1) The width of tissue that would be required for lining and cover of the lip defects are measured separately for upper and lower lip defects. Now, two incisions are carried out slightly obliquely upwards and downwards from the points of the proposed commissure in upper and the lower margins of the defect as shown in Fig. 4a. Two laterally based rhomboid flaps are thus produced. The width of the flaps are equal to the width of tissue required for lining and cover of the excised lip defects as already measured. The flaps included the zygomaticus and platysma muscles. Both the flaps with common base are now pulled medially as shown in Fig 4 a. Excess portions of the flaps were excised. They are now sutured to the mucosal defects of the lips and the cheek. The muscles of the flaps are now sutured to the muscles of the cut margins of the lips. Flaps are now rolled out and sutured with the skin margins (Fig. 4b).

DISCUSSION: The oral commissure is a difficult area to reconstruct because restoration of sphincter function for food retention and speech is as important as achieving appropriate aesthetics and contra-lateral symmetry.

Converse,(2) suggested the use of donor tissue in the descending order of preference; the remaining lip segments, the tongue, the adjacent cheek and the distant sites.

The present authors method of reconstruction is based on the original double rhomboid method described by Jackson. (3) Here the tongue flap is not used for lining of the defect. The muscles of upper and lower flaps in part remains innervated and also regain their innervation through 


\section{CASE REPORT}

neurotisation. Rea et al( ${ }^{(4)}$ proved electromyographic evidence of nerve regeneration in Gillies fan flap of lower lip. Neck dissection was not performed in the two cases of squamous cell carcinomas we operated. However, the lower incision can be extended to the neck from the angle of the lower flap for neck dissection if required.(5,6) There was no recurrence in our case during two years of follow-up. The sphincter function and the cosmetic results were satisfactory.

\section{REFERENCES:}

1. Robotti E et al., Oral commissure reconstruction with orbicularis oris elastic musculomucosal flaps, J Plast Reconstr Aesthet Surg (2009), doi: 10. 1016/j.bjps.2008.11.082.

2. Converse JM. Kazanjian and Converse's surgical treatment of facial injuries, vol.2. Williams \& Wilkins; 1974. Chapter 23, 949-996.

3. Jackson, Ian T., Local flaps in the head and neck reconstruction. The C. V. Mosby Company 1985: 399-412.

4. Rea JL, Davis WE, Rittenhouse LH. Reinnervation of an Abbe-Estlander and a gillis fan flap of lower lip. Arch otolaryngol 1978; 104: 209.

5. R. C. Mishra. Reconstruction of ala of nose and angle of the mouth with nasolabial flap, Indian j. Otolaryngol Head Neck Surg. 1977 Jan; 49(1): 64-65.

6. Madhumati Singh et al., Versatile grafts and flaps in reconstruction of oral and maxillofacial post-surgical defects, International Journal of Head and Neck Surgery, January-April 2011; 2(1): 17-25.

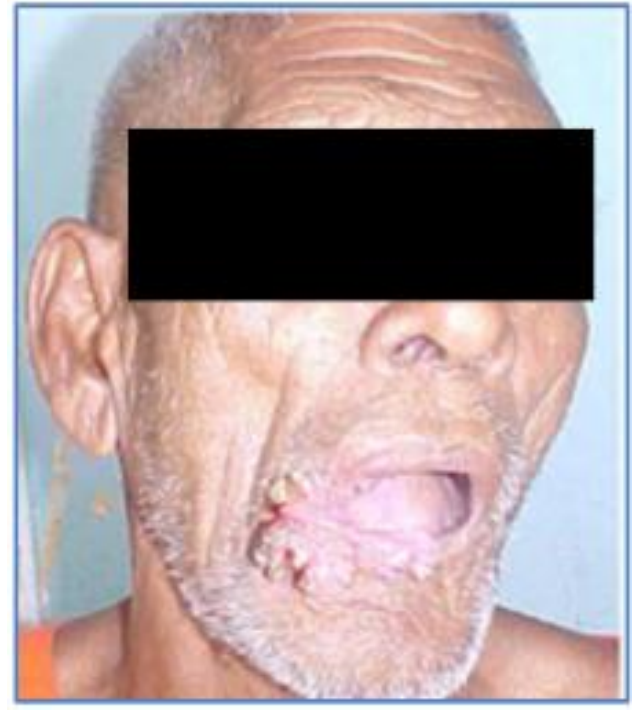

Fig. 1: Squamous Papilloma, left angle of the mouth

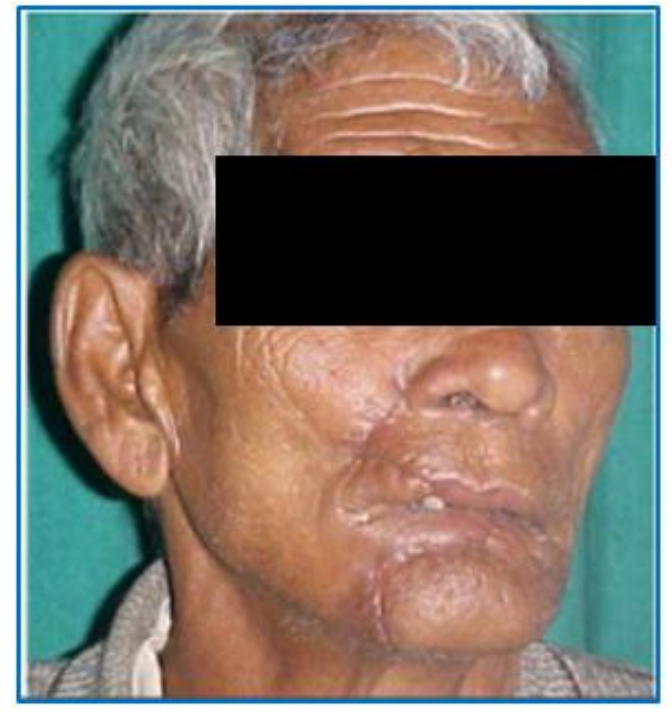

Fig. 2: Post-operative photograph after excision and sphincter preserving reconstruction 


\section{CASE REPORT}

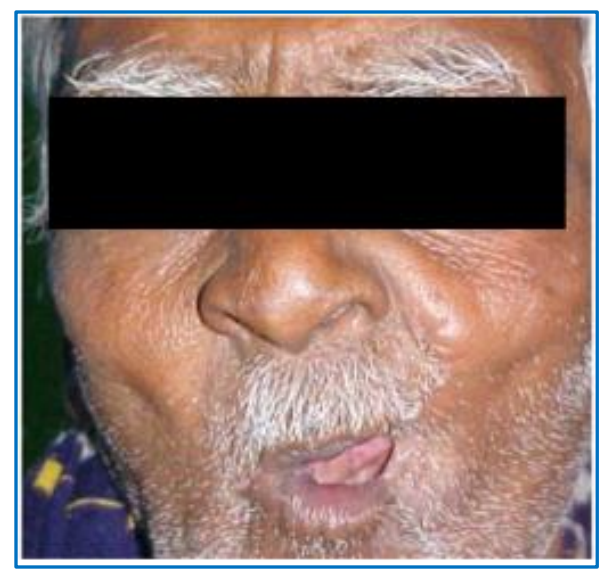

Fig. 3a: Post-Operative Photograph Showing Sphincter Function

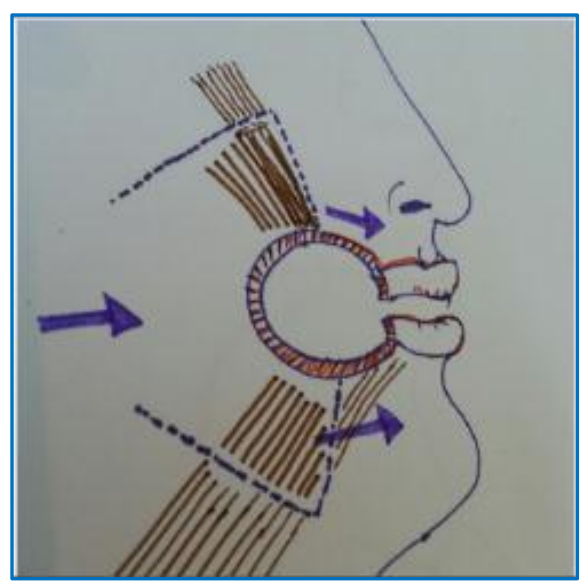

Fig. 4a: Showing the Defect and Outline of the Incisions

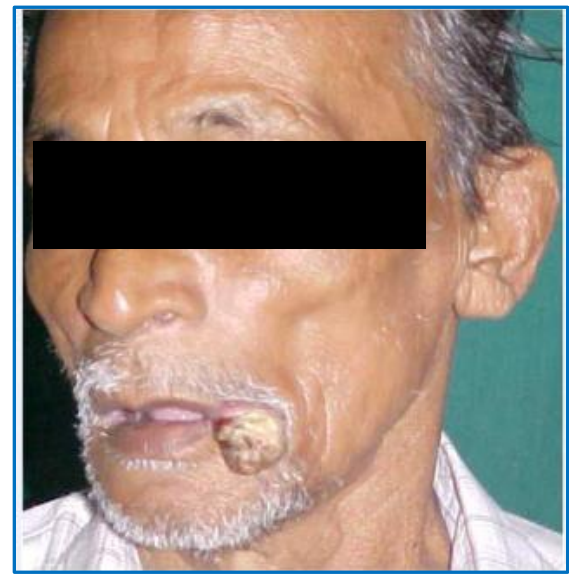

Fig. 5

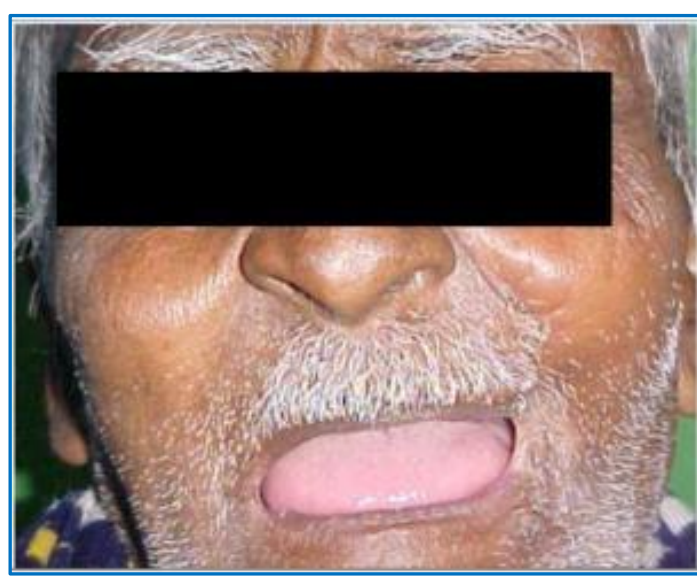

Fig. 3b: Post-Operative Photograph Showing Sphincter Function

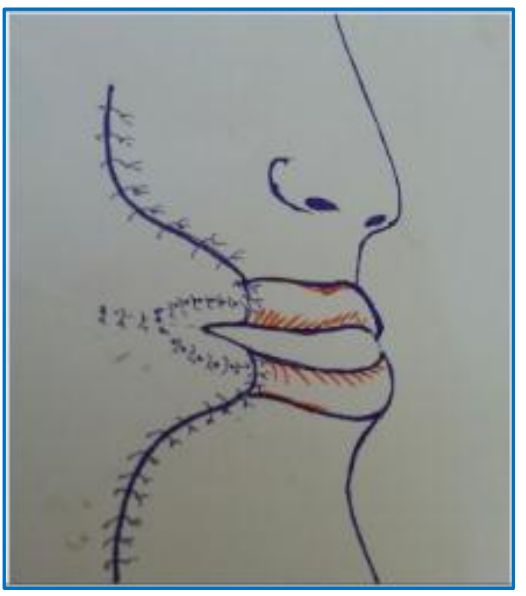

Fig. 4b: Pulling the Flaps Forward, Excising the Extra Tissue and Inset to form cover and Lining

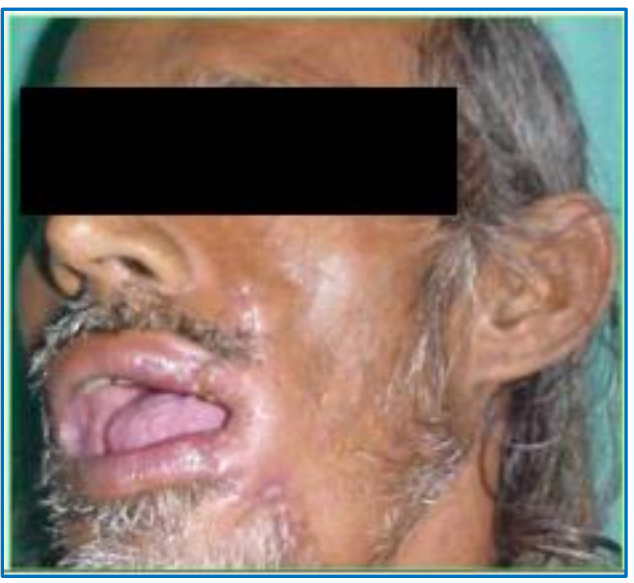

Fig. 5a: Post-Operative Photograph of another PATIENT 


\section{CASE REPORT}

\section{AUTHORS:}

1. Utpal Bordoloi

\section{PARTICULARS OF CONTRIBUTORS:}

1. Associate Professor, Department of Plastic Surgery, Assam Medical College \& Consultant Plastic Surgeon, Srishti Hospitals \& Research Centre, Dibrugarh, Assam.

FINANCIAL OR OTHER

COMPETING INTERESTS: None

\section{NAME ADDRESS EMAIL ID OF THE}

CORRESPONDING AUTHOR:

Dr. Utpal Bordoloi,

Associate Professor,

Department of Plastic Surgery,

Assam Medical College, Dibrugarh.

E-mail: utpalbordoloi50@gmail.com

Date of Submission: 28/04/2015.

Date of Peer Review: 29/04/2015.

Date of Acceptance: 13/05/2015.

Date of Publishing: 21/05/2015. 